\title{
Analysis of Zhang Jian Memorial Hall Design
}

\author{
Dingding Shi*
}

\author{
Interior design, School of Visual Arts, New York City, USA \\ *Corresponding author.Email:dshi@sva.edu
}

\begin{abstract}
With the continuous development of human history and culture, memorial hall has become the embodiment and materialization of people's commemoration of their own emotions, and the expression of emotions and the shape of memorial has also become the focus of memorial architects' research. This paper focuses on the expression of commemorative emotion in the exhibition space of Zhang Jian Memorial Hall in Jiangsu Province, China, and discusses its design concept and how to design the exhibition space through the theory of emotional design, so as to enhance the emotional experience of visitors and highlight the memorial of the memorial hall. As a spiritual carrier of great sages, the construction of Zhang Jian Memorial Hall is designed to present a peaceful and quiet state, giving the audience a plain and low-key impression, but also a sense of complexity in simplicity, elephant invisible.
\end{abstract}

Keywords: Memorial hall, Exhibition, Zhang Jian

\section{INTRODUCTION}

Haimen, known as the "gateway to rivers and seas", is located at the intersection of the Yangtze River and the Yellow Sea, bordering Nantong in the west and the Yangtze River in the south, facing the international metropolis Shanghai across the river. Zhang Jian, a famous industrialist, politician and educator, was born here in the late Qing Dynasty and the early Republic of China. He founded more than 20 enterprises and more than 370 schools in his life, which made outstanding contributions to the rise of modern national industry and the development of education in China, and indisputably became a learning model and spiritual leader for all Haimen people.

As a pioneer and model of Chinese private entrepreneurs, Mr. Zhang Jian actively initiated education and social public undertakings, benefiting the villagers and helping the masses. General Secretary Xi Jinping twice talked about Zhang Jian, saying that he actively launched education and social public welfare undertakings while starting industry, benefiting the township and helping the masses, with far-reaching influence. He is a model of patriotic entrepreneurs and a pioneer and model of China's private entrepreneurs.

The above is our real thinking in the face of Zhang Jian's achievements, Zhang Jian spirit, and haimen culture. It is the best way to know and study Zhang Jian which make us to design Zhang Jian Memorial Hall with the first-class standard pursued by Mr. Zhang Jian all his life. The memorial hall is created to better inherit and carry forward Zhang Jian spirit, better follow Zhang Jian's great footprint, and better create a new humanistic coordinate of Zhang Jian's hometown. We are willing to turn our incomparable reverence and admiration into concrete actions, only in this way can we reflect our humility, admiration and touching to Mr. Zhang Jian.

\section{DESIGN CONCEPT OF ZHANG JIAN MEMORIAL HALL}

\subsection{System concept}

The Memorial Hall of Zhang Jian is a combination of the humanistic atmosphere, historical culture, character inheritance, cultural relics exhibition and historical events in the city, so as to establish an interdependent relationship and form a multifunctional complex historical and cultural block. The construction of the complex historical and cultural block will enhance the cultural atmosphere and historical deposits of the city, and create a new cultural outlook and lifestyle for the city.

In terms of social effect, the construction of Zhang Jian memorial Hall reflects the prosperity and civilization of the city, stimulates the vitality of the city, and overcomes the limitation of pure commercial atmosphere on the future development of traditional culture. 
In the image of the city, it can quickly identify the cultural characteristics of the city and reflect the important symbols of the city. In terms of cultural effect, Zhang Jian memorial Hall greatly improves the traditional cultural life of the city through the aggregation of different functions. At the same time, the overall value of the project is improved through the space combination of business forms and the aggregation of people flow. In terms of function, the complementarity and interaction of life are utilized to form resource sharing to the greatest extent, which greatly improves the living environment and improves people's quality of life.

\subsubsection{Spatial layout system}

The museum adopts $1+7+1$ space layout, namely sequence hall + hall + temporary exhibition hall to form space sequence, giving full play to the spatial advantages of the building. Adhering to the humanistic concept of the layout of the exhibition space design. Zhang memorial exhibition activity oriented is the social public, therefore, the designers in the exhibition space layout design process should follow the ideals of humanism design, in particular, the division of design personnel in the area to visit and tour route set, shall be consistent with the habits of most people, only in this way, only then can we ensure that everyone who enters the museum can get the best and most intimate experience of the exhibits.

\subsubsection{Exhibition Hall Function System}

The museum comprehensively displays Mr. Zhang Jian's extraordinary life course and great achievements, highlights Zhang Jian's spiritual connotation, integrates the functions of education, publicity, reception, academic and development, and realizes the integration and systematization of functions.

\subsubsection{Exhibition design system}

\subsubsection{Exhibition clue system}

The design of the museum takes dream as the main intention and logical clue to run through. Zhang Jian's life is a life of struggle, dream pursuit and rough life. It can be said that Zhang Jian's dream was the dream of national self-improvement, the dream of national rejuvenation and the dream of people's happiness. For this dream, he pursued unremittedly and struggled all his life. In order to his dream, he tapping its practice, die, after a careful study and comb, we think we can dream, connection, tandem fold into, highlighting cultural context and spiritual connotation of the memorial, the atrium as the pursue, the permanent exhibition hall for the dream, in the exhibition hall for a dream, from dream to dream a dream, woven system complete and distinct exhibition clues.

\subsubsection{Exhibition Content System}

The contents of the exhibition fully reflect the academic and scientific nature of Zhang Jian's research, and integrate into the ideological connotation and core value of the new era. In the specific design process, designers should effectively grasp the key contents of the exhibition, and extract the symbols and relevant elements that match the theme, so as to realize the scientific use of the symbols and elements mentioned above in the process of designing the spatial layout. Designers in the exhibition space layout design, should consider the floor of the hall and the visual effect of the ceiling, so that you can combine the exhibition content and the color of the floor and ceiling modelling to grasp and control, at the same time, designers can also use height and distance of the exhibition hall within each partition adjustment, realize the reasonable layout of the space, In order to create the scene atmosphere consistent with the exhibition content.

\subsubsection{Exhibition form system}

In the process of designing the spatial layout, designers should not only ensure that the display function can be reflected, but also ensure that the harmony between different exhibits and different exhibition areas can be achieved. In view of this, designers should pay attention to highlight the multiple utility of space display design in the design, to ensure that visitors can meet the demands of personalized exhibits appreciation, but also to let them feel the unique atmosphere created by the exhibition hall. In order to avoid the deep feeling of exhibition arrangement to visitors, designers should use natural light instead of artificial light, so as to make visitors feel affinity.

\subsubsection{Exhibition color system}

Considering that the exhibition space of the memorial hall is confined space, because in practice, the memorial hall uses artificial light source when laying out the exhibition column. However, artificial light sources tend to cause tension among visitors and make them feel unnatural. In the thematic museum exhibition space, the use of clever color collocation to achieve the coordination of background color and display content[12], highlight the display theme. Combining with the theme of Zhang Jian's dream, the museum will involve seven major colors, endowing the exhibition with connotation and enhancing tension through color aesthetics.

\subsection{Situational idea}

There are many kinds of commemorative emotions, which can be grand, positive and warm, or solemn and sorrowful. When designers express different commemorative emotions, there will be certain 
differences in the use of design techniques for display space. Therefore, fully refining the memorial emotion, understanding and mastering the emotional expression of the memorial exhibition space is the premise for designers to quickly determine the emotional tone of the memorial and choose the design method, and also reflects the feasibility and necessity of the integration of the memorial exhibition space design and emotional design.

The emotion presented in the exhibition space of the memorial hall has its specific main tone. Although the direction of positive emotion or negative emotion is determined, the emotional color is not single. Due to the complexity and diversity of emotions, people's emotions do not exist independently, and there are thousands of links[3], so the emotions contained in the exhibition space of the memorial are often mixed and interwoven.

In the design of the museum, symbolic scene is through the use of architectural and artistic images, relying on symbolic and pictorial architectural language, reading experience and exhibition content complement each other, not only strengthen the sense of history of space, but also effectively expand the audience's sense of scene and sense of immersion. Through the vivid visual language, we can inspire visitors to have a deep feeling of being on the scene by observing the time mark of 100 years ago, the reproduction of art and the real historical scene[4].

\subsection{Targeted concept}

The interpretation of meaning behind the exhibits is one of the criteria the exhibition sets for visitors to judge. Art creation is generated by artists observing the world from the perspective of "self", while visitors are often in a state of "unconscious", moving and observing the complex surface of the exhibits to understand the intention of the author. Whether the prototype image of the author can be accurately conveyed to the audience is influenced by the readability, popularity, rhythm and other factors of the exhibition[5].

Teenagers are the hope of the future, the memorial is a special school, in order to let they grew up in the heart buried the seeds of love township, by showing more than 10 in our memorial embodies Zhang Jian personality cultivation, studying hard, hard work, perseverance, the benefit of the people's story, Zhang Jian inspiring spirit, as descendants of Zhang Jian.

In public exhibition crowd, communication and dialogue between text and emotion, the art guide into readable "art theater" mode, scene exhibition, hierarchical analysis, correlation analysis, from the works of the forming background, the author's emotion, and 4 works is a deep meaning with all-round display, if the journey of exhibition design is architecture framework, Then the content of deepening appreciation is the part of filling the framework, transforming the dull literature into vivid display and expression, and guiding the aesthetic site that resonates with visitors.

\subsection{Economic concept}

Good exhibition design is not based on the premise of high investment, but to achieve the ideal effect in an appropriate way, intelligent means, with the lowest cost to achieve the best balance between exhibition and late maintenance.

The economic system of Zhang Jian memorial hall is mainly based on the inheritance of historical figures, and its economic applicability should be fully considered in the actual architectural design. As the core element of Zhang Jian Memorial Hall, history and culture directly affect the normal operation and profit of the memorial hall. Therefore, in the design, we should ensure that Zhang Jian Memorial Hall has a unique cultural connotation and the best exhibition mode, so as to infect more visitors[6].

\section{MEMORIAL HALL DESIGN}

\subsection{Cultural background and spiritual connotation}

The memorial hall is located at the rear of the central axis of the Cultural park, with a symmetrical architectural pattern, solemn and solemn. As the main building of the whole park, the memorial hall is located on the central axis of the park with the main entrance, which not only reflects the sense of ceremony, but also increases the direction of sight, leading to the memorial hall at the end of the axis, making it a visual focus and cultural highlight. The roof is treated in the Xieshan way, which echoes the Xieshan of the original architecture. The architectural layout emphasizes the space atmosphere of the symmetrical layout of the eclectic style architecture of the Republic of China, and cooperates with the square in front of the museum and greening, forming the design and construction of the whole architectural style of the Republic of China[7]. The interior exhibition adheres to the design concept of basing on tradition and integrating Chinese and Western, combs the culture in the later modern spirit, takes recognizable symbols as the basis of interpretation, and makes every effort to interpret the beauty of harmony between ancient and modern times.

\subsection{Key Points of Design}

The design of the new Zhang Jian Memorial Hall mainly highlights two key points:

One is to reflect the historical sense of Zhang Jian's time, integrate the architectural elements of the late Qing Dynasty and the early Republic of China, create specific scenes and contexts through the carrier of architecture, shorten the psychological distance of visitors, and 
promote a certain degree of sense of immersion. The second is to reflect the appeal of Zhang Jian spirit, which is the core of the memorial design and soul, is the focus, but also difficult.

In order to "a real and a virtual" "a near and a far" of the historical sense and appeal of organic integration, mutual support, we concentrated the architectural language of the memorial hall and extract the "Shenzhou" image, show zhang Jian's spiritual climate and grand pattern, meaning the historical value and practical significance of Zhang Jian spirit. Zhang Jian memorial Hall is not only the "boat of endeavor", but also the "boat of universal love", "boat of ideal", named as the "century ark", the architecture of solemn generous, simple and refined, thick and powerful.

\subsection{Memorial Hall Site selection}

On the position, the new Zhang Jian Memorial Hall is located in the north of the old museum, 74 meters away from the two, representing the extraordinary life course of Mr. Zhang Jian. The new museum and the old museum, Zhang Gong's ancestral hall, screen wall, memorial archway, etc., present a north-south axis pattern, strengthen the memorial hall management area.

In terms of traffic planning, the original road network presents a "two horizontal and three vertical" pattern. "Two horizontal" in addition to zhuangyuan Street, a channel between the new and old management, as a VIP channel, to meet the special needs of reception, at the same time to solve the hidden danger of the old museum without fire access. In the "three longitudinal", in addition to the former S222 provincial Road and Fumin Road, an internal road is added to the west side of the memorial Hall, with both vehicle and pedestrian functions. The entrance of zhuangyuan Street is still used as the main entrance of the Memorial Hall. On the south side of the main entrance, there are temporary gathering and parking functions for tourists. In the entrance setting, south, west, east, a total of four primary and secondary entrances.

In terms of color, the building adopts blue brick, red copper and some stone materials, presenting a simple green gray tone, which complements the surrounding environment and echoes the old museum.

The construction of Zhang Jian Memorial Hall faces south, and the main body stretches from east to west, implying that Zhang Jian spirit runs to the sea along the Yangtze River from west to east. The building is surrounded by waterscape, so that the building lingbo on it, and take haimen local residential "four ting ditch" tradition.

In addition to the south main entrance, the new memorial hall in the DIRECTION of S222 additional entrance, in the direction of fumin Road to set up a logistics entrance, reflecting the office, logistics, support functions.

Therefore, from the north of the old Memorial Museum of Zhang Jian, the new building presents a horizontal sense of stretching from east to west. The horizontal line gives a quiet image and a welcoming posture. The curved line at the top of the building is slightly upturned, just like Mr. Zhang Jian's smile. The image of the five mountains of Nantong on the facade of the building represents the spirit of Mr. Zhang Jian, which is a series of peaks and a treasure house waiting for viewers to discover and explore.

\subsection{Memorial hall design expression}

In order to show the theme connotation of Zhang Jian's "personality charm", the Zhang Jian Memorial Hall is designed from the aspects of architectural layout design, external site design and internal atmosphere design.

\subsubsection{Architectural layout design}

On both sides of the main entrance, there are copper reliefs engraved with 23 "First in China" pictures of Mr. Zhang Jian, so as to present the great achievements of Mr. Zhang Jian one hundred years ago with artistic language and highlight its historical status and height. The two upper peng are also made of copper, decorated with freehand textile elements, which is a metaphor for Zhang Jian's founding of Dasheng Group, as well as the innovation and systematization of Zhang Jian's enterprise. At the same time, the process of inlaying copper in the grooves on the facade of the building appropriately presents the contents of Mr. Zhang Jian's industry, education and charity. The east facade of the building, the upper part of the shape like a sail, so that the building presents a dynamic sense of setting sail.

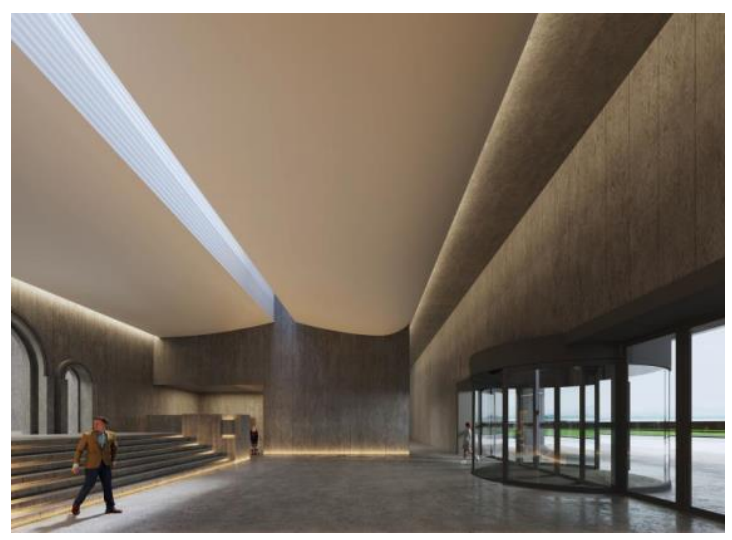

Figure 1 Entrance and exit of exhibition hall 


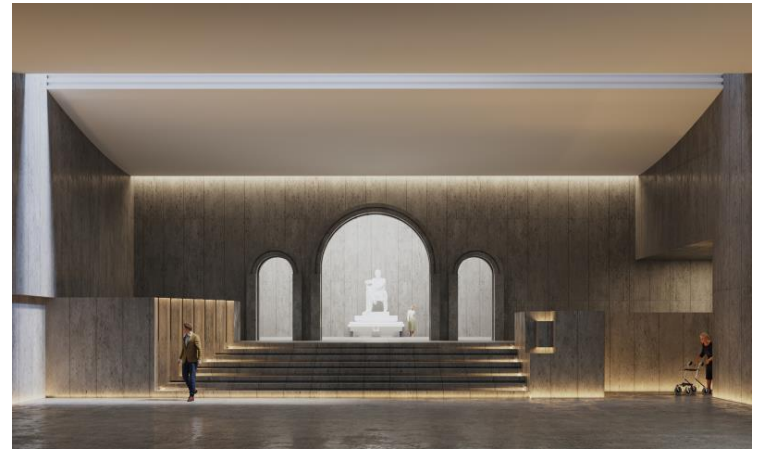

Figure 2 Statue in the hall

In addition, there is a "logistics" entrance and exit.The west facade of the building, as the secondary entrance connecting the S222 provincial road, is divided into the south facade. The same technique is adopted to cement the horizontal sense of the building, but increase the volume of the entrance canopy, and the building facade is connected with the content of the "Five mountains" itself, making the five mountains like a threedimensional long roll picture. The north facade, compared with the other three facades, has rich shape changes. The bottom floor is set with a veranda, which organically combines the internal space of the building with the external environment and increases the enjoyment of sightseeing. On the second floor at the top of the building, a glass corridor is set to form a dialogue between the inner courtyard and the outside on the second floor.

\subsubsection{External site design}

The light and color effect of the corridor space on the second floor relies on the architectural brick window. Colored art glass is used here in the design. The five colors reflect on the plain white wall, which has a unique charm. In fact, colored window glass has long been used in traditional gardens, such as the thirty-six mandarin duck pipes in Suzhou humble Administrator's Garden. We try to innovate, but do not deviate from the spirit of tradition[8-9]. The exhibition space consists of two layers, presenting a "work" shape on the plane. The whole space is rich in layers and has a clear direction. The symmetrical architectural space of the first floor hall creates a solemn and profound cultural and historical context. Viewed from the front, the statue of Zhang Jian is standing inside the gate of Achievement, with pine trees behind it, and a traditional wooden gate of vermillion in the foreground. Here, east and West, tradition and modernity, time and space interact and coexist in harmony. The Door of Achievement effectively houses the two structural columns, increases the depth of field, and has a certain symbolic significance, echoing the tradition, effectively forms the tone of the exhibition space. The right and left walls are respectively the introduction of Zhang Jian and the relief of Zhang Jian culture in stone. The design uses the form of "picture scrolls" to present the wonderful chapters of Zhang Jian's colorful life and remarkable achievements to the audience.

\subsubsection{Internal atmosphere design}

On the plane of Zhang Jian Memorial Hall, two sections are formed, representing two major courses of Zhang Jian's life, namely, "from studying to becoming an official" and "from an official to entering business" respectively. The previous paragraph with birth and growth as the main content, to the end of the top scholar. The latter part is about Mr. Zhang Jian's journey of "abandoning official to start business" in order to realize the dream of saving the country, which contains rich and colorful contents such as industry, education and charity, and is the main content of zhang Jian memorial Hall. The two sections are arranged in a clockwise direction along the viewing flow.

In addition, a temporary exhibition hall is set up on the east side of the building. The exhibition activities related to Zhang Jian can be planned and exhibited from time to time, which is a necessary supplement for the main exhibition of the memorial hall.

The main body of the second floor of the building is multi-functional hall and academic lecture hall, and other auxiliary Spaces with the same number of relevant, such as office, warehouse, etc., to meet the daily operation and management needs of the memorial hall.

The exhibition space is about 3,600 square meters over two floors. Visitors walk through the hall, give up and enter the atrium. We take the atrium as the preface hall, and turn left into four chapters: growth, industry, education, and charity. On the escalator, there are three chapters of politics, art and heritage on the second floor. After the visit, the visitors take the elevator or take the spiral staircase to the first floor through the tea rest area, and enter the temporary exhibition hall through the glass corridor to continue their visit. The temporary exhibition hall has an independent entrance and exit. Entering this chapter, a huge oil painting of Zhang Jian with MEDALS hung on his chest is hung head on. The chronology of Zhang Jian is engraved on the wall in the shape of a scroll on the left hand, and the auspicious cloud pattern is designed on the top. The extraordinary narrative is opened with the usual tone, and the source of dream (imperial examination arduous journey is great champion of the world), the great dream is rooted in reality. We set a high expecnation and this time Zhang in the face of western powers ring four is a man whistled, he awakens people must have their own dream, this is the origin that Zhang dream, this chapter USES the color of the earth, better hall with golden yellow as the highlights, so Zhang big break and the peak of life, his life began. The Door of Dream (from official to businessman, industry to save the country). One hundred years ago, Zhang Jian, with his broad mind and extraordinary vision, awakened and led 
the Chinese people to open the door of industry, selfreliance, hard work and realize the dream of a powerful country. Using the color of the sea, blue is the main tone of the color of this hall, Zhang Jian's cause riverside sea, blue five elements belong to water, water all things do not speak. Zhang Jian's life and major career are almost closely related to water, design to open and turn the exhibition path, reflect Zhang Jian's thought and practice of saving the country, to create a career of rough and difficult. The industrial layout unit, located in the sacred cylindrical space, symbolizes the height and breadth of Mr. Zhang Jian's industrial empire, reproduces the outer gate of Dasheng textile factory, and leads visitors back to the historical scene through time and space. Then around the rotunda, come to the third chapter, education - Dream of the Soul (open the people's wisdom education to rejuvenate the country). In Zhang Jian's opinion, the strength of a country is based on education, and the dream of education is the spirit and soul of chapter dream. This chapter is the core display of the memorial hall, presenting Zhang Jian's successful exploration of rejuvenating the country through education, showing Zhang Jian's dream of educating talents, saving the nation and striving for survival. The design adopts the color of grass and trees, trees in 10 years, people in 100 years. Education is the highlight of Zhang Jian's life and career, casting the foundation of Nantong's leading basic education in China today. As a result, Nantong education has been inherited from generation to generation. The design of tongzhou Teachers' Table is the beginning of Mr. Zhang Jian's education. At the same time, by restoring the gate of Nantong public Stadium, we highlight Zhang Jian's comprehensive and far-reaching plan for education. After this chapter, we will come to the fourth chapter, charity chapter - Flower of Dream (helping the whole country with its hometown). Zhang Jian thought that charity was the only thing beyond industrial education. This chapter shows Zhang Jian's extraordinary achievements in charity and his profound feelings of helping the whole world. The design adopts the color of flowers, and Mr. Zhang Jian's charity is like a nursery, with fragrance of flowers and spring in the air. The audience will deeply feel Mr. Zhang Jian's charity concept of loving, caring and benefiting the people by restoring the photos of Zhang Jian brothers and centenarians in nursing homes, civilian factories and invalides. Then take the escalator to the second floor, and move to the fifth chapter, Political Chapter - Dream Wing (family and national feelings to save the country to cure).

Zhang Jian has single-handedly initiated the events of a city to realize the dream of a country. Wandering in the politics of the time, hard work, painstaking, determined to build an emerging world, design using cotton iron color. The cotton iron theory advocated by Mr. Zhang Jian is in essence a political pursuit for the Chinese people to control their economic lifeline. This chapter shows Zhang Jian's political ambition, political ideal and political practice in the late Qing Dynasty and the early Ming Dynasty, as well as his special role and contribution on the Chinese political stage, and the far-reaching influence. After this chapter, cross the bridge into chapter 6 , art chapter : The rhyme of Dreams (poetry and chapter art meaningful and outstanding). Besides industrialist, educator and philanthropist, Zhang Jian also made great achievements in study, literature, opera, embroidery, architecture and other fields. The article adopts the color of ink and wash. Mr. Zhang Jian popularized the flow of culture and art into People's Daily production and life and integrated it into the urban construction and development of Nantong, reflecting the integration of water and ink.

As the first city in modern times, Nantong has left a strong mark in the history of Urban development in China.

Finally, passing through Mr. Zhang Jian's Baotan site of the Yangtze River is chapter 7, inheritance chapter - The light of dreams (living in the corner of the light). Zhang Jian's cause and spirit have been shining up to now. Baotan scene is the last portrait of Zhang Jian's life. Zhang Jian's achievements in many fields and his material wealth and spiritual wealth have influenced the future generations up to now. His personality charm and family and country feelings are still of great practical significance. The design adopts the color of sunrise and the light of Mr. Zhang Jian's thought and spirit to guide future generations.

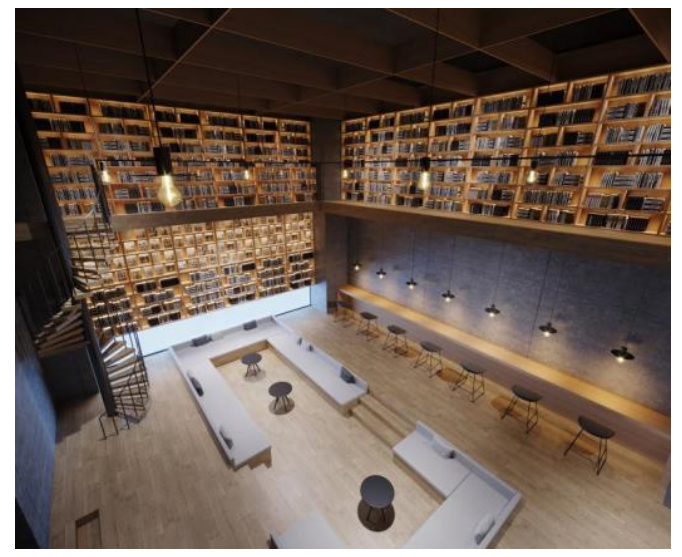

Figure 3 Reading room in the hall

As the wine culture exhibition hall inside the memorial hall, Yisheng wine has a history of more than 100 years. The design of the exhibition hall refuses to be modern and commercialized. Instead, it should be a cultural space with a heavy sense of history and traditional characteristics[10-11]. At the same time, it will become a wine culture space for visitors to enjoy, enjoy and enjoy. The design adopts the garden-style spatial processing method[11], organically combines the function and form through the elements of wall doors, climbing corridors and pavilions, and creates a gardenstyle three-dimensional wine culture exhibition space with both north and south characteristics. 


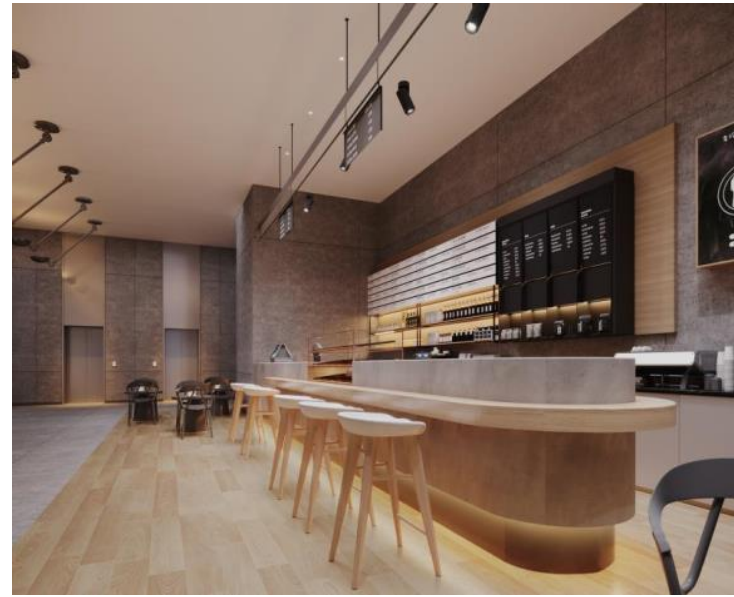

Figure 4 Chateau in the hall

The souvenir shop is the "end" of the whole exhibition space, which is transformed from the original office into a space with traditional wooden door pages and six fully open doors. It forms its own characteristics and features while continuing the exhibition space of Yisheng wine culture. The antique furniture and sparkling top create a warm and quiet small space.

\section{CONCLUSION}

Memorial hall is a multi-functional social institution integrating collection, research, display and education. Exhibition is the central link of the memorial hall to serve the society and the audience. The exhibition layout of the whole building of Zhang Jian Memorial Hall in Jiangsu, China is prominent and dense. The exhibition style is concise, smooth and rhythmic, integrating functionality with artistry, academia and appreciation. Architectural design adopts artistic expression to strengthen the landscape, scene and humanized design, reflecting the unity of content and form, science and innovation, education and leisure.

Zhang Jian Memorial Hall is tailored for Mr. Zhang Jian, architectural form, color, material, image, traffic, landscape, especially the internal exhibition, all from this goal, to the upgraded version of the old museum, innovative version. The new museum relies on the old museum and surpasses the old one, and the old museum echoes the new one and becomes a whole by itself, realizing the harmonious unity of the new and old buildings. It not only demonstrates Mr. Zhang Jian's character of inclusiveness and innovation, but also embodies the Nantong spirit of Zhang Jian's posterity.

\section{REFERENCES}

[1] P. Violi, Educating for Nationhood: A Semiotic Reading of the Memorial Hall for Victims of the Nanjing Massacre by Japanese Invaders (Eds.), Journal of Educational Media, Memory, and Society, vol. 4, 2012, pp. 41-68.
[2] S. Bhattacharya, Taj of the Raj: appropriating the colonial legacy of Kolkata's Victoria Memorial Hall (Eds.), Nineteenth-Century Contexts, vol. 41, 2019, pp. $1-21$.

[3] H. K. Sen, Victoria Memorial Hall Kolkata Engineering, Architecture, Conservation \& Modernisation (Eds), Proceedings of the Institution of Civil Engineers - Engineering History and Heritage, 2020.

[4] W. Ling, Research on the Expression of Regional Cultural Elements in the Design of Museum Exhibition Space (Eds.), Frontiers in Art Research, vol. 2, 2020.

[5] R. M. Alan II, Exhibiting memory: Temporary, mobile, and participatory memorialization and the Let Paul Robeson Sing! Exhibition (Eds.), Memory Studies, vol. 13, 2018 . DOI:https://doi.org/10.1177/1750698018794771.

[6] C. Federica, Representing indigenous soldiers at the Australian War Memorial: a political analysis of the art exhibition (Eds.), Australian Journal of Political Science, vol. 55, 2020.

[7] Z. A. Imanbayeva, A. M. Assylbekova, L. T. Nurkusheva, I. I. Ostapenko, D. A. Amandykova. ON THE HISTORY OF STUDYING MUSEUM COMPLEXES (Eds.), Astra Salvensis, 2019.

[8] R. BoA, P. Federico, C. G. Ta, Analyzing the Museum Experience Through the Lens of Instagram Posts (Eds.), Curator: The Museum Journal, vol. 64, 2021.

[9] M. K. Maria, J. F. Jensen, Learning through exploration at museum exhibitions (Eds.), Museum Management and Curatorship, vol.36, 2021.

[10] J. Higashi, The Destruction and Creation of a Cityscape in the Digital Age: Hiroshima Peace Memorial Museum (Eds.), Museum International, vol. 70, 2018.

[11] J. M. Chia, Museum and Hagiography: The Ashin Jinarakkhita Memorial Hall in Jakarta (Eds.), Material Religion, vol. 13, 2017. 